\title{
SPEAKING ANXIETY IN ENGLISH CONVERSATION CLASSROOMS AMONG THAI STUDENTS
}

\author{
Songyut Akkakoson \\ Faculty of Applied Arts \\ King Mongkut's University Technology North Bangkok Thailand \\ songyutbee@gmail.comkkakoson
}

\begin{abstract}
Purpose - This paper reports on a part of a larger research project concerning the conceptualisation of English language speaking-inclass anxiety, attitudes to speaking English in class and self-ratings of English-speaking ability, and perceived sources of this situationspecific anxiety.
\end{abstract}

Methodology - The participants in this study were 282 Thai university students of English as a foreign language (EFL) studying English Conversation courses at a university in Thailand. Levels of anxiety (on average and by dimensions) were investigated through questionnaires adapted from the Foreign Language Classroom Anxiety Scale (FLCAS). Attitudes towards oral English, self-ratings of English-speaking ability and sources of speaking anxiety were collated through semi-structured interview forms.

Findings - The quantitative analysis indicated the existence of speaking-in-class anxiety among Thai EFL students at a moderate level. Levels of anxiety by dimensions, namely test-anxiety (TA), fear of negative evaluation (FNE) and communication apprehension (CA), were found to be moderate as well. However, TA and FNE were significantly dominant performance anxieties. Qualitatively, students' positive attitudes towards speaking English in the classroom were reflected, whereas a negative rating for their spoken English ability was reported. Finally, the limited repertoire of students' vocabulary was found to be their major source of speaking anxiety. 
Significance - This research urges awareness of anxiety-provoking factors in the EFL classroom as learners' ability to communicate satisfactorily is both the learners' goal of learning and the instructor's goal of teaching. The findings have pedagogic implications in terms of affective aspects of learning, for students when making an effort to overcome speaking-in-class anxiety and for instructors when attempting to create a low-anxiety classroom.

Keywords: Foreign language anxiety, English language speakingin-class anxiety, test-anxiety, fear of negative evaluation, communication apprehension.

\section{INTRODUCTION}

As an instructor of English as a foreign language in a Thai university, the present researcher entered his English Conversation classes in the hope that students will interact with him enthusiastically through English. However, what he found was the reverse of what it should be. When posed a question or asked to do any speaking activity, most of his students became a crowd of silent onlookers while some stuttered in their replies. At first, this inability to perform in class led to the researcher's inaccurate perception that 'the student lacks either some necessary aptitude for learning a language or sufficient motivation to do the necessary work for a good performance' as suggested by Horwitz, Horwitz, and Cope (1986, p. 127). In fact, it might have been anxiety that played its negative role here. As a result, the interaction that the researcher looked forward to turned out to be incomprehensible input and non-feedback output.

For those EFL learners, speaking is considered the most important language skill to be mastered since English is in a powerful position as a medium for international communication (Crystal, 2003) and yet it is assumed to be the most stressful among the four language skills (Young, 1992; Hauck \& Hurd, 2005; Liu, 2009; Öztürk and Gürbüz, 2014). Living in the EFL environment, these learners face limitations on the use of the target language i.e, lack of sufficient exposure to the language itself and shortage of opportunities to speak the language. As a result, learners may be under pressure and be vulnerable to anxiety once they are required to communicate through English in 
the classroom (Oxford, 2002). This may end in non-feedback output to the instructor. This scenario is a consequence of the psychological factors which play an important part in the language learning process. One of these factors which is well documented is anxiety. Generally speaking, anxiety is described as "a subjective feeling of tension, apprehension, nervousness, and worry associated with an arousal of the autonomic nervous system" (Spielberger, 1983, p. 1). Anxiety can be divided into three categories: trait anxiety, situational anxiety and state anxiety. Language anxiety is recognised as a construct of situation-specific anxiety, mainly independent of the other types of anxiety (Horwitz et al. 1986). Influenced by two seminal articles, Scovel's (1978) and Horwitz et al. (1986), a number of studies on language anxiety have been carried out over the past four decades. These studies have employed measures to identify the anxiety experienced by learners in particular second/ foreign language contexts. In view of the importance of anxiety as one of the factors influencing oral communication performance, later researchers have also examined the role of anxiety in speaking (e.g. Woodrow, 2006; Liu, 2007; Inthakanok, 2009-2011; Subaşi, 2010; Mak, 2011; Heng, Abdullah, \& Yusof, 2012; Agudo, 2013; Öztürk \& Gürbüz, 2013; Zhiping \& Paramasivam, 2013; Öztürk \& Gürbüz, 2014). What these researchers have found include different levels of oral anxiety (ranging from low to high) experienced by a considerable number of learners in different learning contexts. But the consistent finding is that anxiety forms an essential element that could determine learners' oral production.

The present study explored the construct of speaking-in-class anxiety of Thai EFL undergraduate students. It aimed to identify speaking anxiety as an important factor in leaner attitudes towards English. It also tried more specifically to find out the situations that provoked anxiety. Based on these objectives, three research questions were formulated:

1. What are the levels of speaking-in-class anxiety among students in the English Conversation course?

2. What are the student's attitudes towards speaking in English Conversation classrooms and their self-ratings of Englishspeaking ability?

3. What are the students' sources of speaking-in-class anxiety? 
The findings could help to make Thai EFL university students aware of the factors that might impede their English-speaking process so that they could find suitable ways to overcome their anxiety problems. As English will definitely be used for occupational purposes when these students leave the university and enter working circles, it is important to ensure that they can perform well in English. Moreover, research into factors that may affect successful oral communication, and adaptation to the social and academic environment would be beneficial to teachers of English who endeavour to turn their English-speaking class from a stressful and anxious environment to the one that boosts its students' innate communication strengths.

\section{METHODOLOGY}

The study took a sample of Thai university students who registered for the elective English Conversation I and II courses, of which the present researcher was one of the instructors. Totally, 282 students responded to the questionnaires and 88 students responded to the semi-structured interview forms. Two data collection instruments were employed to obtain both the quantitative and qualitative data - the Modified Foreign Language Classroom Anxiety Scale (MFLCAS) and the Student Interview Form (SIF). Designed as a student questionnaire, the MFLCAS was adapted from the Foreign Language Classroom Anxiety Scale (FLCAS) developed by a group of pioneer researchers in the field, Horwitz et al. (1986). Widely adopted and adapted by a number of later researchers, the FLCAS was designed as a self-report tool for drawing out responses of anxiety specific to foreign language classroom settings. When first constructed, its internal reliability achieved "an alpha coefficient of .93 with all items producing significant corrected item-total scale correlations" (Howitz et al., 1986, p. 129). The MFLCAS consists of two parts. The first part collects the respondents' personal and academic information and the second part surveys their perceptions on speaking-in-class anxiety using the form of a 33-item Likerttype response scale survey, on which the respondents express their perspectives on English-speaking anxiety by responding to either (5) strongly agree, (4) agree, (3) neither agree nor disagree, (2) disagree, or (1) strongly disagree. In order to interpret the analysed data, the following criteria were established: 
- A mean score of $4.21-5.00$ would indicate the highest level of anxiety.

- A mean score of $3.41-4.20$ would indicate high-anxiety level.

- A mean score of $2.61-3.40$ would indicate medium-anxiety level.

- A mean score of $1.81-2.60$ would indicate low-anxiety level.

- A mean score of $1.00-1.80$ would indicate the lowest level of anxiety.

As foreign language anxiety concerns performance evaluation within an academic and social context, all questions in the second part represent three related performance anxieties, namely communication apprehension, test-anxiety and fear of negative evaluation. Designed as a written response form, the SIF was used to gather students' opinions on English-speaking anxiety. The SIF forms were purposively distributed to the student participants who were studying in the researcher's classes. However, not all of the given forms were returned. Only 88 of the returned forms were used in the final analysis. For construct validity, both the MFLCAS and the SIF were translated into Thai and the Thai versions were validated by three experts in the field of Applied Linguistics. As a result, items on both research instruments scored greater than 0.50 on the index of item objective congruence test, consistent with expert judge validity. See Appendix for sample items of the two instruments.

\section{RESULTS AND DISCUSSION}

\section{The Level of Speaking-in-Class Anxiety}

Research Question 1 was set to find out whether there was any anxiety among students when speaking English as a foreign language in the classroom. Data for this research question were collected using the MFLCAS. To determine the level of speaking-in-class anxiety of the participants, the mean scores were calculated using descriptive statistics. 
Table 1

An Overview of Speaking-in-Class Anxiety

\begin{tabular}{lccc}
\hline \multicolumn{1}{c}{ Level of Speaking-in-Class Anxiety } & $n$ & Mean & $S D$ \\
\hline On average Medium-anxiety & 282 & 3.13 & 0.57 \\
\hline By dimension & & & \\
Test-Anxiety (TA) & 281 & 3.27 & 0.93 \\
Fear of Negative Evaluation (FNE) & 274 & 3.22 & 0.63 \\
Communication Apprehension (CA) & 269 & 3.03 & 0.55 \\
\hline
\end{tabular}

The overall statistical result shown in Table 1 reports that the students in this study generally experience a moderate level of English-speaking anxiety. The average mean score obtained falls within the range of 2.61 to 3.40 , which is the medium-anxiety level. It can be said that generally Thai university students in this study are moderately anxious about oral communication in English. The level of their perceived anxiety is neither high nor low. This is perhaps because these students may think that being able to speak English as a foreign language in Thailand is a necessity-cum-non-necessity. That is, there is still some reluctance on their part to become involved in this language as they have not yet seen its distinct advantage. If they try to improve their speaking ability, the immediate benefit is that they may get high marks in this subject, but at the same time they do not have difficulty communicating in a monolingual society like Thailand where there is no relevant need to learn a foreign language when all dealings can be done in the native language. This finding corroborates those of Inthakanok (2009-2011) and Heng et al. (2012), but it is different from what ÖztÜrk and GÜrbÜz (2014) and Agudo (2013) have found. The majority of ÖztÜrk and GÜrbÜz's (2014) Turkish students generally experience a low level of EFL speaking anxiety as they may realise that being able to speak English in Turkey is beneficial to them in most of the areas, thus striving for an improvement in their speaking ability in their language class with not much worry. The Spanish subjects of Agudo (2013), by contrast, experience relatively high levels of speaking anxiety despite being long time learners of EFL. The researcher concludes that foreign language anxiety "is not necessarily characteristic or exclusive to beginners because experienced learners also suffer it" (p. 842). 
When considering the levels of anxiety by dimensions, it is found that the average mean score of each dimension falls within the medium-anxiety level. However, it is obvious that test-anxiety (TA) and fear of negative evaluation (FNE) are significantly dominant performance anxieties, whereas communication apprehension (CA) ranks third. Based on the ANOVA, the mean score of FNE is significantly different from that of CA at the .05 level (sig. .005) and the mean score of $\mathrm{CA}$ is significantly different from that of TA at the .05 level (sig. .000), whereas the mean scores of FNE and TA are not significantly different. It can be said that fear of negative evaluation and test-anxiety are major factors that may evoke English-speaking anxiety among the students in this group, whereas a less frequent factor is communication apprehension. An explanatory reason for the fear of being in the assessment process may rest with the fact that these students consider speaking English at this stage as their classroom activity involving their performance appraisal, rather than as communicating with others in the wide world through English. Thus, they are afraid of being appraised by the instructor, which might lead to failing the course. As for the fear of negative evaluation, it is an outcome which is consistent with Subaşi's (2010) findings for the Turkish classrooms. A plausible explanation for this as proposed by Horwitz et al. (1986) is due to students' uncertainty of themselves and what they are saying. Thus, they may believe that they are not able to make appropriate social impressions, which means their peers or classmates' judgements in the case of the present study. Perhaps they may be concerned about being teased by their classroom friends. Gregersen and Horwitz (2002) further explain that these anxious students may think they seem stupid when speaking a foreign language in front of peers, which allows for negative evaluation. This fear may eventually turn into frustration and apprehension, resulting in avoiding speaking in order not to seem foolish in others' views. However, communication apprehension, although not prevalent in this study, is dominant in Woodrow's (2006) study. She found that the most frequent source of anxiety is interacting with native speakers which is the most referred to out-of-class stressor. Woodrow explained that these students are living in the target language environment in which daily life oral communication plays its role. The influence of communication apprehension is also partly supported by the findings of Mak (2011) who used factor analysis to examine the thirty-three item FLCAS of 
Horwitz et al. (1986). Mak combined comprehension apprehension or speech anxiety and the fear of negative evaluation of Horwitz et al. as one factor and she found that it is the most important factor contributing to ESL speaking-in-class anxiety, accounting for $20.4 \%$ in her study. This is due to the fact that students have a feeling of worry about speaking in an English class and fear of embarrassment when negatively judged by others.

\section{Student Attitudes and Perceived Ability towards Speaking in English Conversation Classrooms}

Research Question 2 deals with surveying students' attitudes towards oral English and rating their perceived English-speaking ability. The open-ended questions 1 and 2 in the SIF ask how the 88 participants feel about speaking English in class and how they rate their oral performance.

\section{Table 2}

Student Attitudes and Perceived Ability

\begin{tabular}{|c|c|c|c|c|}
\hline \multirow[t]{2}{*}{ \# } & \multirow[t]{2}{*}{ Questions } & \multicolumn{3}{|c|}{ Students $(n=88)$} \\
\hline & & Positive & Negative & No Idea \\
\hline 1. & Attitudes towards speaking English in class & $62(70.45 \%)$ & $21(23.86 \%)$ & $5(5.68 \%)$ \\
\hline 2. & Average speaking ratings & $40(45.45 \%)$ & $48(54.54 \%)$ & - \\
\hline
\end{tabular}

Contrary to the quantitative results which showed that these students experienced a moderate level of EFL speaking anxiety while being in class, $70.45 \%$ of those who were interviewed reflected positive opinions about speaking English in the classroom. Among these students, some of them reported that:

"It's fun although being shy at first."

"It's fun as it is practice and development of my English use."

"It's fun with trial and error learning from my mistakes.

I'm kind of more confident to speak up."

The above excerpts indicate three points of discussions. First, what the students said may serve as an illustration of the negative 
correlation between the speaking anxiety they perceived and the attitude to oral English they expressed. Their utterances showed that they are optimistic about speaking English in class-affective reactions towards the language-learning situations, which could involve attitudes towards the instructor, the class, the textbooks, and the language laboratory (Gardner \& MacIntyre, 1993, p. 2). Second, the emergence of these positive views is most likely due to the fact that the students' anxieties may decrease after the course continues to progress. Once they are on familiar terms with their classmates and the instructor, the learning-teaching atmosphere in class will become friendly. This may lead to the students' bravery being gradually built up to take the risk of speaking English in class. Third, the fact that one student saying, "It's fun although being shy at first." and the other saying, "It's fun with trial and error learning from my mistakes. I'm kind of more confident to speak up." are probably the outcomes of facilitating/beneficial anxiety, which impacts the students in a positive and motivating way. Perhaps, the students may be able to do better than they might think because of this positive facet of anxiety as it might keep them poised, careful and alert. Thus, it can be concluded that these students may be aware of the negative correlation between the two affective variables-speaking anxiety and attitude to oral English. Their situation-specific anxiety becomes less over time and their facilitating/beneficial anxiety plays its role.

On the other hand, 21 students (23.86\%) expressed negative feelings about their English Conversation classrooms. Some of them stated that:

"I felt nervous when I couldn't respond immediately as I couldn't think of the words."

"I'm embarrassed and shy when speaking English as I can't think of the right words."

"I'm slow in making sentences."

The above opinions, although given by just around one-third of the interviewees, may serve as an exemplification that speaking is seen an anxiety-evoking variable in the language learning process. This finding is paralleli with previous studies which show that speaking 
is a source of anxiety among various ethnic groups of learners in different learning contexts (e.g. Horwitz et al., 1986; Woodrow, 2006; Inthakanok, 2009-2011; Mak, 2011; ÖztÜrk \& GÜrbÜz, 2014). From an early study on foreign language anxiety like that of Horwitz et al. (1986) to those in the present time, speaking anxiety seems to be fairly typical of learners of L2 or foreign language. As Horwitz et al. (1986) mentioned, anxious students fear speaking in the foreign language. They dare not risk showing themselves speaking another foreign language in front of others. They are afraid of not understanding all the language input because for them to comprehend the target language means that they need to know every spoken word. In class, these students may sit in the back row in order not to be humiliated or embarrassed by being called on to speak. At their best, they may study excessively, but they may skip class at their worst. In any circumstance of speaking a foreign language, anxious students do not want to make mistakes, feeling that they are tested all the time and every correction they received meant a failure. It can be concluded that foreign language in-class anxiety is situation-specific and uniquely different from other kinds of anxiety as students who are anxious perceive that a language learning task is impossible to be dealt with (Horwitz et al., 1986). Similarly, EFLspeaking anxiety "may be a separate phenomenon other than general foreign language anxiety and it should also be investigated in other contexts" (ÖztÜrk \& GÜrbÜz, 2014, p. 14).

Although $70.45 \%$ of the interviewed participants expressed positive attitudes towards speaking English in the classroom, 54.54\% of them and not approve of their English-speaking ability. This reveals the fact that these students lacked the confidence to speak English in the classroom even though they were well aware that using the target language in the conversation class was necessary. Perhaps this problem might be solved by resorting to allowing students to partly use their L1 in class. In her study of Chinese students in Hong Kong, Mak (2011) allowed her students to use Chinese in the ESL classroom in order to lessen speaking anxiety in the classroom. She argues that, "the use of L1 will build learners' confidence and, in turn, encourage speaking" (p. 212) and that the amount of L1 to be used should not be so much that it blocks students' exposure to the target language. 


\section{Sources of Speaking Anxiety}

Research Question 3 aims to find out the sources of the speakingin-class anxiety. A total of 126 responses were obtained from the student interviewees $(n=88)$. Various points were reported as the reasons for speaking-in-class anxiety. Altogether, six anxietyevoking factors were identified.

Table 3

Students' Reported Sources of Speaking Anxiety

\begin{tabular}{|c|c|c|c|}
\hline Sources of Anxiety & & Number of Responses & Percentage $(\%)$ \\
\hline Vocabulary repertoire & & 48 & 38.09 \\
\hline Self-confidence & & 19 & 15.08 \\
\hline Chances to speak English & & 19 & 15.08 \\
\hline Grammar/language accuracy & & 18 & 14.28 \\
\hline Attitude to English & & 18 & 14.28 \\
\hline Background of English & & 4 & 3.17 \\
\hline & Total & 126 & 100.00 \\
\hline
\end{tabular}

Limited vocabulary was viewed by $38.09 \%$ of the students as a major factor; lack of self-confidence $(15.08 \%)$, having no chance of speaking English in their daily lives (15.08\%), inaccurate use of grammar/language $(14.28 \%)$ and negative attitudes towards English (14.28\%) are considered as less frequent factors, while poor background of English (3.17\%) as a minor source of anxiety. These answers can be considered as basic reasons for speaking anxiety which can be further classified into three groups: individual, environmental and educational. The first group of factors which contains the most reasons is the individual factors, namely vocabulary repertoire, self-confidence, grammar/accuracy and attitude towards English. These factors can be viewed as important elements of producing English utterances, but they are what these individual students lack, thus making them anxious when they have to converse in English. The second group includes only one factor; chances to speak English. Since these students live in a monolingual country, Thailand, where all routine activities can be successfully made through their mother tongue, exposure to oral communication in English is rare for them. Therefore, they are likely to be nervous 
when having to speak in English. The last category involves one factor which is poor background of English. Even though these students have learned English from their mainstream schools for at least nine years, their English language skills are not good enough. This can be ascribed to the fact that the English curricula in Thailand place emphasis on grammar, a little writing and reading and rote learning, and not listening and speaking (Akkakoson, 2013; Kunnu \& Sukwises, 2014). Definitely, this brings about anxiety when it comes to students' aural reception and oral production in English.

The fact that this group of students viewed vocabulary as the most important factor for them to speak English is interesting. This finding is consistent with that of Liu (2007) whose participants confirmed that lack of vocabulary was a main cause for their anxiety in oral English classrooms. A reasonable explanation for this is that students cannot understand others or express their own ideas without sufficient vocabulary. This is true according to Wilkins (1972) who wrote that "... while without grammar very little can be conveyed, without vocabulary nothing can be conveyed" (pp. 111112). We can imagine ourselves experiencing different languages; even without grammar, with some useful words and expressions, we can communicate. Lewis (1993) also argued that "lexis is the core or heart of language" (p. 89). Predominantly when students develop greater fluency and expression in English, it is necessary for them to gain more helpful vocabulary knowledge and expand their own personal vocabulary learning strategies. It is due to the intrinsic nature of language learning that students often recognise the importance of vocabulary. As Schmitt (2010) put it, "learners carry around dictionaries and not grammar books" (p. 4). Thus, learning vocabulary helps students master English for their purposes, and teaching vocabulary helps them understand and communicate with others in English.

Moreover, the above perceived sources of anxiety are both consistent and contrasting with those of previous researchers. Inthakanok (2009-2011) who also studied speaking anxiety of Thai university students found that high anxiety participants in his study reported multiple sources of anxiety. The major sources of anxiety included audience and grammar/accuracy, while the minor sources involved lack of self-confidence, past experience and English attitudes. The lack of self-confidence or self-perception of poor speaking ability in 
the target language is also identified as a potential source contributing to foreign language speaking anxiety in the study of Kitano (2001). In addition, ÖztÜrk and GÜrbÜz (2014) found that foreign language anxiety arises from three major sources: fear of making mistakes, a perfectionist attitude and reactions of other students.

\section{CONCLUSION}

This study dealt with the conceptualisation of anxiety in communicating in English through the perspectives of Thai university students in a normal language-learning context. The research assumed EFL-speaking anxiety to be debilitating and identified its existence. The level of speaking anxiety experienced by 282 students was revealed via a questionnaire, while attitudes and perceived sources of anxiety from 88 students were collated through an interview form. The results provided evidence that there exists English-speaking anxiety among Thai students. This anxiety is considered situation-specific, present especially in classroom situations in which learners are particularly stressful (Horwitz et al., 1986). Although a moderate level of oral English anxiety was found generally, and a negative self-evaluation of English-speaking ability was reported in this study, the students reflected positive attitudes towards speaking English in the classroom. Speaking of the levels of anxiety by dimensions, test-anxiety and fear of negative evaluation became more frequent performance anxieties than communication apprehension. Moreover, a limited repertoire of vocabulary was perceived as the students' most important source of speaking anxiety.

The study has implications for EFL learners and EFL teachers. Students who are learning English as a foreign language should be aware of a worried feeling which may arise from related performance anxieties (i.e. fear of failing the test, fear of negative evaluation, and communication apprehension) and from being unable to produce oral utterances due to lack of basic elements, particularly having a limited repertoire of vocabulary. As the ability to communicate satisfactorily in English is the ultimate aim of the learners, these factors of anxiety can contribute to their negative attitudes towards the language class, their overall levels of foreign language anxiety, their speaking-in-class anxiety, their oral performance and eventually their grades when meeting compulsory requirements to speak. As it 
is apparent that anxiety comes from an individual learner's feeling, Inthakanok (2009-2011) suggests that "[t]his could be further applied to awareness-raising that the learners might be largely responsible for their own anxiety" (p. 93). That is, it is the learner's responsibility to control his/her anxiety or to find suitable strategies to minimise or get rid of that debilitating feeling as it evidently ruins one's oral performance. Liu (2007) has also noted that students' achievement comes after their hard working, persistence and determination. EFL students should accept that speaking-in-class anxiety exists and have recourse to anxiety-coping strategies. Improvements in their English proficiency, expansion of their vocabulary repertoire, having more oral practice of English and preparedness for oral English lessons are necessities.

For EFL instructors, the knowledge that students' worries over speaking the language exists should not be overlooked. Although they appear to be happy and enjoying the lessons the instructor provides in class, anxiety may play its role when it comes to one's having to express utterances out loud in front of others in a foreign language. Instructors should be aware of the influence from themselves over what is taught as "some of their own reactions [...] can possibly increase or decrease students' anxiety of speaking in class" (Zhiping \& Paramasivam, p. 8). A good example of this can be viewed from some EFL respondents in the study of Nazara (2011) who felt that they would be criticised strongly by their lecturers for incorrectly pronouncing English words. If the instructor does not pay attention to this affective filter (Krashen, 1982), his/her interpretation of students' reluctance to speak or silence during classroom interaction may be wrong. The instructor may solely ascribe students' inability to perform in class to such reasons as their lack of aptitude for learning the target language, their insufficient language background, their inadequate motivation to attend to in-class practice for a better language performance, or their too much sticking to the textbook content. In actual fact, this inability may arise from learners' anxiety to perform in the target language orally. Moreover, stages of anxiety should not be ignored (Woodrow, 2006) as some learners may have anxiety because of their lack of skills or "skills deficit" (p. 324). Students' English skill levels should also be considered when preparing the lessons. Two suggestions are given here for instructors to deal with learners' speaking anxiety: a) coach them in managing any existing anxiety-evoking situation and b) make the learning environment more relaxed. 
First, the anxious individuals could be helped by familiarising them with language learning strategies and by scaffolding of skills. These may include asking students not to give up when speaking; preparing words, phrases, or sentences prior to speaking; studying to improve speaking; engaging in positive self-talk, or keep on smiling and volunteering comments. Self-talk or thoughts about themselves that pass through their minds can support students' goals and drive them to succeed (Swan, 2011). If students are aware of the power of positive self-talk, they may have the potential to bring about positive changes in their oral performance.

Moreover, increasing students' motivation might also be a good idea. This was the case in the study of Subaşi (2010) who found that if a student trusts his abilities to do something, he/she will not be anxious. Apart from that, a wider variety of strategies for reducing general language anxiety and those linked with emotions, beliefs, attitudes and motivation can also be found in the work of Oxford (2013). Besides, Nagahashi (2007) has suggested using co-operative learning techniques to reduce language anxiety and increase opportunities for students to speak.

As vocabulary emerges as a major stressor in this study, the teacher can encourage students to have an English dictionary at hand. With the explosion of Smartphone popularity nowadays, there is a large variety of dictionary applications available on students' mobile phones. New generation students can learn new words from these applications with ease.

Second, a less stressful classroom environment could help to reduce students' stress. Although foreign language learning, like the one in this study, inevitably occurs in a formal educational setting where learners' performance assessment is a major requirement, instructors might try their best to make the learning context less nerve-racking. This may involve certain behaviours from the instructor such as: (a) less stressful error correction and performance evaluation methods, (b) classroom relaxation activities, (c) supportive and friendly characteristics and (4) promoting the advantages of L1 utilisation in the classroom. In a similar vein, Liu (2007) suggested that English teachers should create a friendly, supportive and non-threatening classroom-learning atmosphere; invent and arrange various in-class activities to help students to become better acquainted during the 
first few sessions and coach and guide them to have a supportive relationship with one another in class. This is because "students' motivation along with a good relationship between students-teacher and students themselves in class can actively support the amount of success for students by taking part in speaking tasks" (Derakhshan, Tahery, \& Mirarab, 2015, p. 520). Moreover, one more important point that Stewart and Tassie (2011) and Zheng (2008) suggested is recognising cultural differences of the students in the classroom. These may include individual perspectives, religious beliefs, voices of different genders, or racial origins. Cultural differences in class should be employed as a means to produce an attentive, inclusive and hospitable atmosphere.

For future studies, the current study suggests that qualitative instruments like diary writing, think aloud protocols, classroom observations, or teacher reflections be employed to deepen the knowledge of speaking-in-class anxiety. The effectiveness of partly utilising learners' L1 in the speaking classroom is worth investigating. The relationship between speaking anxiety and other affective variables such as self-esteem, inhibition, motivation, risktaking, extroversion is also another interesting research area.

\section{ACKNOWLEDGEMENTS}

This research was funded by King Mongkut's University of Technology North Bangkok (KMUTNB) under contract no. KMUTNB-GEN-57-34. I am indebted to all the participants for their contribution to this study. I owe a debt of gratitude to the managing editor and the other two anonymous reviewers for their constructive feedback, which has facilitated in elucidating several points. Lastly, a special acknowledgement is given to the authors and writers whose names are listed in the References and whose works have given the researcher ideas and inspiration for this research.

\section{REFERENCES}

Agudo, J. D. M. (2013). An investigation into Spanish EFL learners' anxiety. RBLA, Belo Horizonte, 13(3), 829-851. 
Akkakoson, S. (2013). The relationship between strategic reading instruction and student learning how to use L2-based reading strategies and L2 reading achievement. Journal of Research in Reading, 36(4), 422-450.

Crystal, D. (2003). English as a global language (2nd ed.). Cambridge: Cambridge University Press.

Derakhshan, A., Tahery, F., \& Mirarab, N. (2015). Helping adult and young learners to communicate in speaking classes with confidence. Mediterranean Journal of Social Sciences, 6(2), 520-525.

Gardner, R. C., \& MacIntyre, P. D. (1993). A student's contributions to second language learning. Part II: Affective variables. Language Teaching, 26, 1-11.

Gregersen, T., \& Horwitz, E. K. (2002). Language learning and perfectionism: Anxious and non-anxious language learners' reactions to their own oral performance. The Modern Language Journal, 86, 562-571.

Heng, C. S., Abdullah, A. N., \& Yusof, N. B. (2012). Investigating the construct of anxiety in relation to speaking skills among ESL tertiary learners. 3L: The Southeast Asian Journal of English Language Studies, 18(3), 155-166.

Horwitz, E. K., Horwitz, M. B., \& Cope, J. (1986). Foreign language classroom anxiety. The Modern Language Journal, 70(2), $125-132$.

Hauck, M., \& Hurd, S. (2005). Exploring the link between language anxiety and learner self-management in open language learning contexts. European Journal of Open, Distance and E-Learning, 2. Retrieved from http://www.eurodl.org

Kitano, K. (2001). Anxiety in the college Japanese language classroom. The Modern Language Journal, 85(4), 549-566.

Krashen, S. D. (1982). Principles and practice in second language acquisition. Oxford: Pergamon.

Kunnu, W., \& Sukwises, A. (2014). Teaching speaking skills to adult English language learners through ALM. International Journal of Social, Education, Economics and Management Engineering, 8(8), 2702-5.

Inthakanok, I. (2009-2011). Speaking anxiety of a group of Thai EFL university students: Its sources and coping strategies. Journal of Education Silapakorn University, 1-2, 82-101.

Lewis, M. (1993). The lexical approach. Hove: Language Teaching Publications. 
Liu, M. (2007). Anxiety in oral English classrooms: A case study in China. Indonesian Journal of English Language Teaching, 3(1), 119-137.

Liu, M. (2009). Reticence and anxiety in oral English lessons. Bern: Peter Lang.

Mak, B. (2011). An exploration of speaking-in-class anxiety with Chinese ESL learners. System, 39, 202-214.

Nakahashi, T. L. (2007). Techniques for reducing foreign language anxiety: Results of a successful intervention study. Annual Research Report on General Education, Akita University, 9, 53-60.

Nazara, S. (2011). Students' perception on EFL speaking skill development. Journal of English Teaching, 1(1), 28-43.

Oxford, R. (2002). Sources of variation in language learning. In R. B. Kaplan (Ed.), The Oxford handbook of applied linguistics (pp. 245-252). Oxford: Oxford University Press.

Oxford, R. L. (2013). Teaching \& researching: Language learning strategies (2nd ed.). New York, NY: Routledge.

ÖztÜrk, G., \& GÜrbÜz, N. (2013). The impact of gender on foreign language speaking anxiety and motivation. Procedia-Social and Behavioral Sciences, 70, 654-665.

ÖztÜrk, G., \& GÜrbÜz, N. (2014). Speaking anxiety among Turkish EFL learners: The case at a state university. Journal of Language and Linguistic Studies, 10(1), 1-17.

Schmitt, N. (2010). Introduction to applied linguistics (2nd ed.). London: Hodder Education.

Scovel, T. (1978). The effect of affect on FL learning: A review of the anxiety research. Language Learning, 28(1), 129-142.

Spielberger, C. D. (1983). Manual for the state-trait anxiety inventory. Palo Alto, CA: Consulting Psychologists Press.

Stewart, F., \& Tassie, K. E. (2011). Changing the atmos'fear' in the public speaking classroom. International Journal of Humanities and Social Science, 1(7), 9-13.

Subaşi, G. (2010). What are the main sources of Turkish EFL students' anxiety in oral practice? Turkish Online Journal of Qualitative Inquiry, 1(2), 29-49.

Swan, J. (2011, February 24). Re: Positive self-talk-examples [Online forum comment]. Retrieved from http://joanswan. blogspot.com/2011/02/positive-self-talk-examples.html

Wilkins, D. A. (1972). Linguistics in language teaching. London: Edward Arnold. 
Woodrow, L. (2006). Anxiety and speaking English as a second language. RELC Journal, 37(3), 308-328.

Young, D. J. (1992). Language anxiety from the foreign language specialist's perspective: Interviews with Krashen, Omaggio Hadley, Terrell and Rardin. Foreign Language Annals, 25(2), $157-172$.

Zheng, Y. (2008). Anxiety and second/foreign language learning revisited. Canadian Journal for New Scholars in Education, 1(1), 1-12.

Zhiping, D., \& Paramasivam, S. (2013). Anxiety of speaking English in class among international students in a Malaysian university. International Journal of Education and Research, 1(11), 1-16. 


\section{APPENDIX}

\section{Modified Foreign Language Classroom Anxiety Scale (MFLCAS)}

\begin{tabular}{|l|l|l|l|l|l|l|}
\hline 1. & $\begin{array}{l}\text { I never feel quite sure of myself when I am speaking in } \\
\text { my English conversation class. }\end{array}$ & 4 & 3 & 2 & 1 \\
\hline 2. & $\begin{array}{l}\text { I don't worry about making mistakes in the English } \\
\text { conversation class. }\end{array}$ & 4 & 3 & 2 & 1 \\
\hline 3. & $\begin{array}{l}\text { I tremble when I know that I'm going to be called on in } \\
\text { the English conversation class. }\end{array}$ & 5 & 3 & 2 & 1 \\
\hline 4. & $\begin{array}{l}\text { It frightens me when I don't understand what the teach- } \\
\text { er is saying in English. }\end{array}$ & 5 & 4 & 3 & 2 & 1 \\
\hline 5. & $\begin{array}{l}\text { It wouldn't bother me at all to take more English class- } \\
\text { es in the same academic term. }\end{array}$ & 5 & 4 & 3 & 2 & 1 \\
\hline 6. & $\begin{array}{l}\text { During the English conversation class, I find myself } \\
\text { thinking about things that have nothing to do with the } \\
\text { course. }\end{array}$ & 5 & 4 & 3 & 2 & 1 \\
\hline 7. & $\begin{array}{l}\text { I keep thinking that the other students are better at lan- } \\
\text { guages than I am. }\end{array}$ & 5 & 4 & 3 & 2 & 1 \\
\hline 8. & $\begin{array}{l}\text { I am usually at ease during tests in my English conver- } \\
\text { sation class. }\end{array}$ & 5 & 4 & 3 & 2 & 1 \\
\hline 9. & $\begin{array}{l}\text { I start to panic when I have to speak without prepara- } \\
\text { tion in the English conversation class. }\end{array}$ & 5 & 4 & 3 & 2 & 1 \\
\hline 10. & $\begin{array}{l}\text { I worry about the consequences of failing my English } \\
\text { conversation class. }\end{array}$ & 5 & 4 & 3 & 2 & 1 \\
\hline 11. & $\begin{array}{l}\text { I don't understand why some people get so upset over } \\
\text { English conversation classes. }\end{array}$ & 5 & 3 & 2 & 1 \\
\hline
\end{tabular}

\section{Student Interview Form (SIF)}
1. How do you feel about speaking English in class?
2. How do you rate your English speaking?
3. What are your sources of anxiety in speaking English? 